\title{
Indoleamine 2,3-dioxygenase-expressing dendritic cells form suppurative granulomas following Listeria monocytogenes infection
}

\author{
Alexey Popov, ${ }^{1}$ Zeinab Abdullah, ${ }^{2}$ Claudia Wickenhauser, ${ }^{3}$ Tomo Saric, ${ }^{4}$ Julia Driesen, ${ }^{1}$ \\ Franz-Georg Hanisch, ${ }^{5,6}$ Eugen Domann, ${ }^{7}$ Emma Lloyd Raven, ${ }^{8}$ Oliver Dehus, ${ }^{9}$ \\ Corinna Hermann, ${ }^{9}$ Daniela Eggle, ${ }^{1}$ Svenja Debey, ${ }^{1}$ Trinad Chakraborty, ${ }^{7}$ \\ Martin Krönke, ${ }^{2}$ Olaf Utermöhlen, ${ }^{2}$ and Joachim L. Schultze ${ }^{1}$
}

\begin{abstract}
${ }^{1}$ Molecular Tumor Biology and Tumor Immunology at the Clinic I for Internal Medicine, ${ }^{2}$ Institute for Medical Microbiology, Immunology and Hygiene, ${ }^{3}$ Institute for Pathology, ${ }^{4}$ Institute for Neurophysiology, ${ }^{5}$ nnstitute for Biochemistry II, and ${ }^{6}$ Center for Molecular Medicine, University of Cologne, Cologne, Germany. ${ }^{7}$ Institute of Medical Microbiology, University of Giessen, Giessen, Germany. ${ }^{8}$ Department of Chemistry, University of Leicester, Leicester, United Kingdom. ${ }^{9}$ Department of Biochemical Pharmacology, University of Konstanz, Konstanz, Germany.
\end{abstract}

\begin{abstract}
Control of pathogens by formation of abscesses and granulomas is a major strategy of the innate immune system, especially when effector mechanisms of adaptive immunity are insufficient. We show in human listeriosis that DCs expressing indoleamine 2,3-dioxygenase (IDO), together with macrophages, are major cellular components of suppurative granulomas in vivo. Induction of IDO by DCs is a cell-autonomous response to Listeria monocytogenes infection and was also observed in other granulomatous infections with intracellular bacteria, such as Bartonella benselae. Reporting on our use of the clinically applied anti-TNF- $\alpha$ antibody infliximab, we further demonstrate in vitro that IDO induction is TNF- $\alpha$ dependent. Repression of IDO therefore might result in exacerbation of granulomatous diseases observed during anti-TNF- $\alpha$ therapy. These findings place IDO $^{+}$DCs not only at the intersection of innate and adaptive immunity but also at the forefront of bacterial containment in granulomatous infections.
\end{abstract}

\section{Introduction}

Restriction of parenchymal and systemic spreading of intracellular bacteria, such as Mycobacterium tuberculosis or Listeria monocytogenes, is achieved by granulomatous structures or abscesses containing cellular and acellular components. The major role in this process has been attributed to an intricate cooperation among macrophages, neutrophils, and T cells (1-3).

Listeria infection in mice has been exploited extensively as a model to study molecular mechanisms of early innate as well as adaptive immunity $(4,5)$. During systemic L. monocytogenes infection in mice, macrophages are central to the early innate immune response, acting as both hosts for and major defenses against this pathogen (6, 7). Macrophages have also been the major cell type used in the analysis of cell-autonomous defense mechanisms that these cells had to evolve to counterbalance microbial attack $(2,8,9)$.

For entry into host epithelial cells, $L$. monocytogenes requires interaction of the bacterial surface protein internalin A with E-cadherin while internalin B binds to the hepatocyte growth factor receptor (Met), the receptor for the globular head of the complement factor $\mathrm{C} 1 \mathrm{q}(\mathrm{gC} 1 \mathrm{qR})$, and glycosaminoglycans (10). Humans are mainly infected with $L$. monocytogenes via the gastrointestinal tract (foodborne disease) while in mice, enteral infection is not efficient due to a single amino acid substitution in murine E-cadherin $(11,12)$. Healthy humans usually clear L. monocytogenes infection with little or no clinical symptoms. However, in patients with predisposing

Nonstandard abbreviations used: CSD, catscratch disease; EIA, enzyme-linked immunoassay; hk, heat killed; IDO, indoleamine 2,3-dioxygenase; immDC, immature DC; LTA, lipoteichoic acid; $\mathrm{PGE}_{2}$, prostaglandin $\mathrm{E}_{2}$; rhIDO, recombinant human IDO Conflict of interest: The authors have declared that no conflict of interest exists. Citation for this article: J. Clin. Invest. 116:3160-3170 (2006). doi:10.1172/JCI28996. conditions, such as diabetes mellitus, liver failure, HIV infection, immune suppression, splenectomy, older age (> 75 years), and pregnancy, or undergoing anti-TNF- $\alpha$ therapy, listeria can cause a potentially life-threatening disease with clinical symptoms ranging from local inflammatory responses to meningoencephalitis, sepsis with suppurative granulomas in multiple organs, or devastating maternal/fetal infection in pregnant women $(13,14)$. In these patient populations, the incidence is as high as 210 cases per 100,000 (as compared with 0.7 per 100,000 cases in healthy individuals), and mortality can reach $30 \%$ (13).

A major role of DCs during early enteral L. monocytogenes infection has been recently suggested by immunohistochemical studies in rats (15). DCs phagocytose L. monocytogenes in the small intestine after the bacteria cross the intestinal barrier and are the major cells transporting L. monocytogenes to the draining mesenterical lymph nodes. DCs have to manage a delicate balance. On one hand, they have to allow the escape of $L$. monocytogenes from phagosomes and enable subsequent replication in the cytosol in order to promote delivery of L. monocytogenes antigens into the MHC class I-restricted antigen processing and presentation pathways. This is essential for induction of CD8 ${ }^{+} \mathrm{CTL}$, a prerequisite for sterile elimination of L. monocytogenes $(3,16-18)$. On the other hand, intracellular replication must be tightly controlled in order to prevent destruction of DCs, which would result in both lack of CTL induction and systemic spreading of bacteria. Thus, DCs had to evolve mechanisms controlling the number of viable intracellular $L$. monocytogenes (15, $19,20)$. For at least one subtype of murine DCs, production of TNF- $\alpha$ and iNOS has been implicated in innate immune functions of DCs (21). Human and murine immature DCs (immDCs) efficiently internalize L. monocytogenes in vitro, which is followed by rapid DC maturation accompanied by secretion of cytokines, 

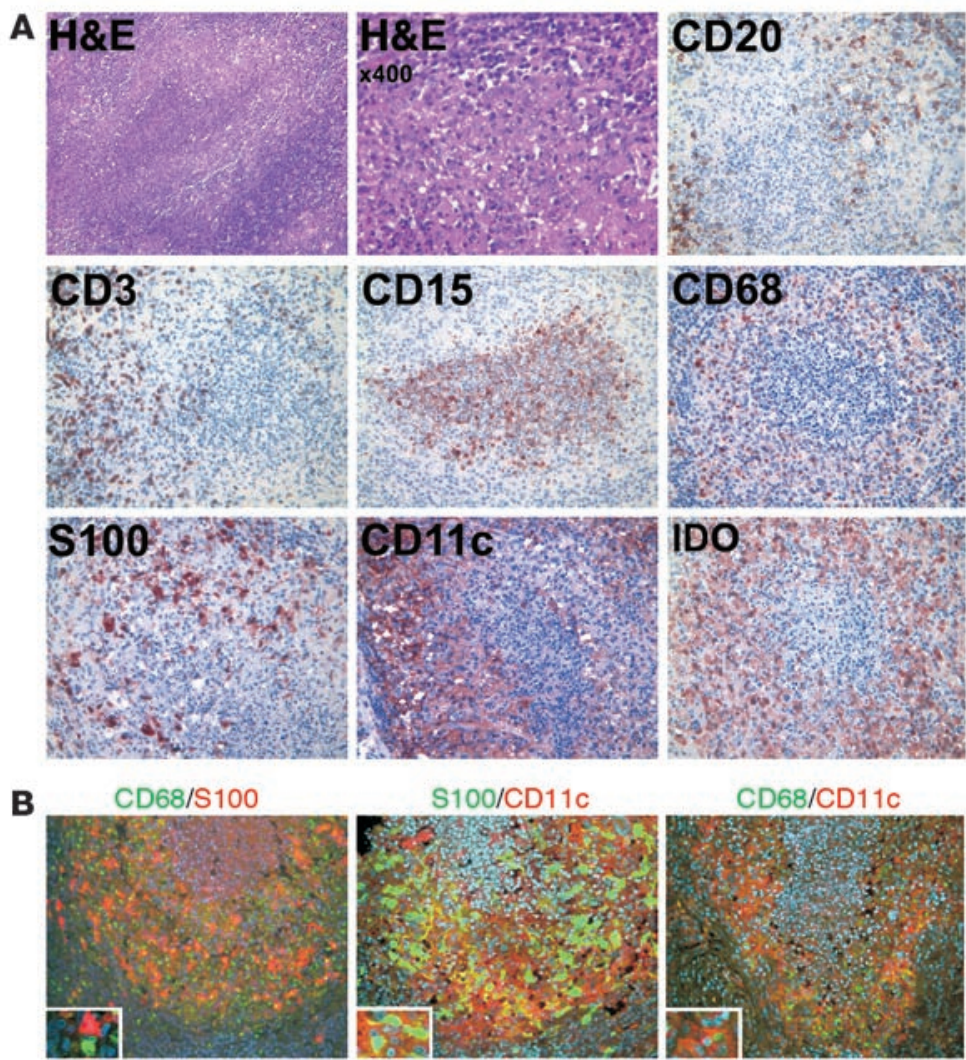

S100/IDO
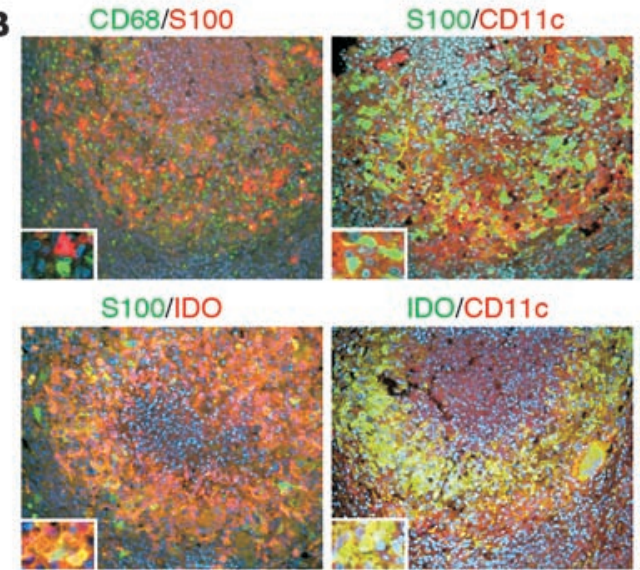

IDO/CD11C
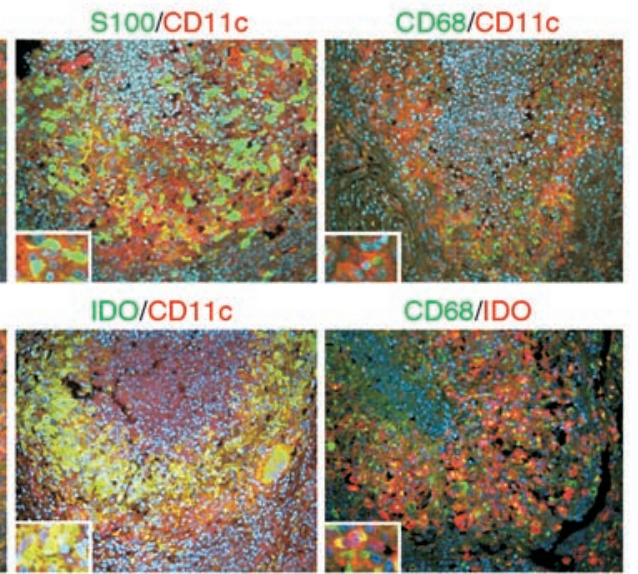

CD68/IDO

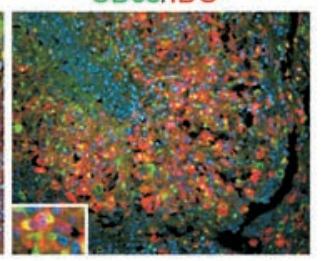

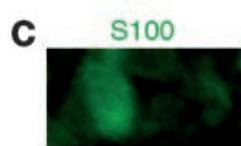

CD68

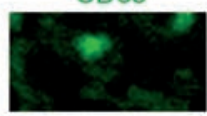

IDO

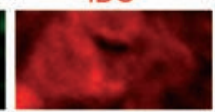

IDO

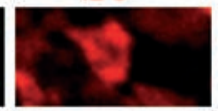

Overlay

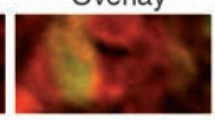

Overlay

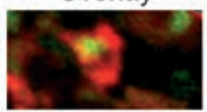

including IL-12 or IL-18, the latter inducing neutrophil activation and migration. In vitro, these DCs can induce significant $\mathrm{T}$ cell proliferation $(17,22,23)$.

These findings suggest that DCs, in addition to macrophages and neutrophils, play a role during early steps of innate immunity to enteral L. monocytogenes infection. While many aspects of early host-pathogen interactions have been described, surprisingly little is known about the cellular components and mechanisms responsible for the formation of granulomas during advanced-stage listeriosis in patients with impaired adaptive immunity.

Here we show for what we believe is the first time that DCs, along with macrophages, are a major cellular component of the outer ring wall of suppurative granulomas in human listeriosis. Moreover, DCs and macrophages within the ring wall strongly express the immunoregulatory enzyme indoleamine 2,3-dioxygen-

\section{Figure 1}

Human DCs in L. monocytogenes infection. (A) Histomorphology of lymph node sections from a patient with suppurative granulomatous listeriosis. H\&E staining of a sample slide with prominent ring-wall formation of histiocytoid cells around suppurative granulomas in listeriosis. Magnification, $\times 100$ and $\times 400$ (H\&E panels). Photographs of immunohistochemical staining with CD20, CD3, CD15, CD68, S100, CD11c, and IDO are shown. Magnification, $\times 250$. One out of 3 comparable cases is depicted here. (B) Immunofluorescence of the same patient samples described above. S100 and CD68 were combined to distinguish between DCs and macrophages. S100 and CD11c were combined to determine a myeloid origin of the S100+ DCs. As a second marker for macrophages, double staining with CD68 and CD11c was performed. To assess expression of IDO by myeloid cells, DCs, and macrophages, analysis of IDO was combined with S100, CD11c, or CD68. One out of 3 cases is presented. Magnification, $\times 250$. In each lowerleft corner, an enlarged section of the photo is shown for more detail (magnification, $\times 2500$ ). (C) Confocal microscopy (Olympus FluoView FV1000 Confocal Microscope) clearly confirms the colocalization of IDO with S100 and CD68. Magnification, $\times 2500$.

ase (IDO). With in vitro studies of human DCs, we show that IDO induction is TNF- $\alpha$ and IFN- $\gamma$ dependent following infection of DCs with L. monocytogenes.

\section{Results}

$I \mathrm{O}^{+} \mathrm{DCs}$ are a major component of granulomas in listeriosis. Lymphadenopathy is a hallmark of advanced listeriosis and is characterized by specialized suppurative granulomas with typical ring-wall formation (24). To better understand the cellular reactions involved in this process, we studied the components of the abscesses in lymph node specimens of 3 patients with serologically confirmed cervico-glandular-type infection with L. monocytogenes. Bacterial genes were verified in the diseased lymph nodes by PCR (Supplemental Table 1 and Supplemental Figure 1; supplemental material available online with this article; doi:10.1172/JCI28996DS1). H\&E staining revealed large numbers of the typical granulomas with ring-wall formation accompanied by follicular and interfollicular hyperplasia (Figure 1A). Using markers specific for B cells (CD20) and T cells (CD3), we demonstrated that these specialized cells of the adaptive immune response are not part of granulomas in listeriosis but are almost exclusively located in between granulomas. Since macrophages and neutrophils are known to play major roles in systemic listeriosis in murine models $(8,25,26)$, we next assessed expression of CD15 (granulocyte marker) (27) and CD68 (macrophage marker) (28) in infected tissues (Figure 1A). Within the center of the granulomas, basically all cells were $\mathrm{CD} 15^{+}$granulocytes, with only a few $\mathrm{CD}^{2} 8^{+}$macrophages. The number of $\mathrm{CD} 68^{+}$cells within the ring walls was variable among different granulomas in the same lymph node specimen, ranging from $30 \% \mathrm{CD}^{+} 8^{+}$cells up to $70 \%$ of all cells forming the ring wall. Unexpectedly, there was a high number of S100+ DCs (29) within this area while only a few DCs were found within the center of the granulomas or outside the ring-wall structure (Figure 1A). The clear separation of $\mathrm{T}$ and $\mathrm{B}$ cells in the 
A

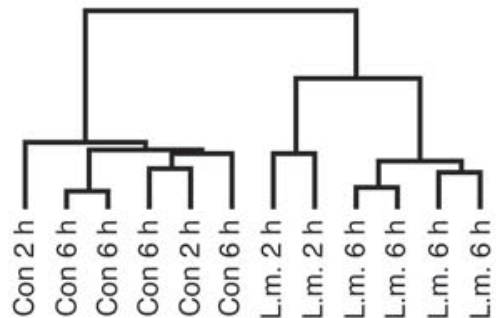

B

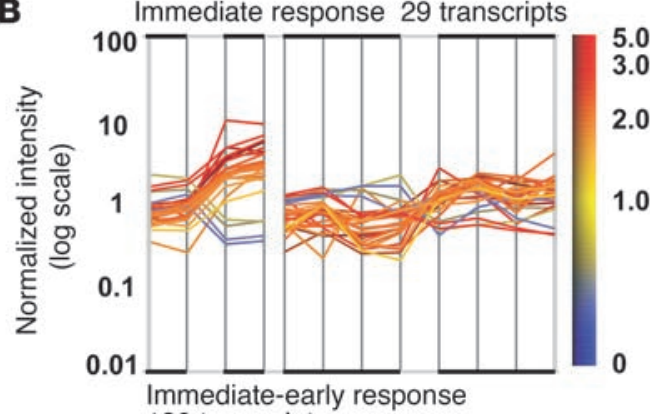
130 transcripts
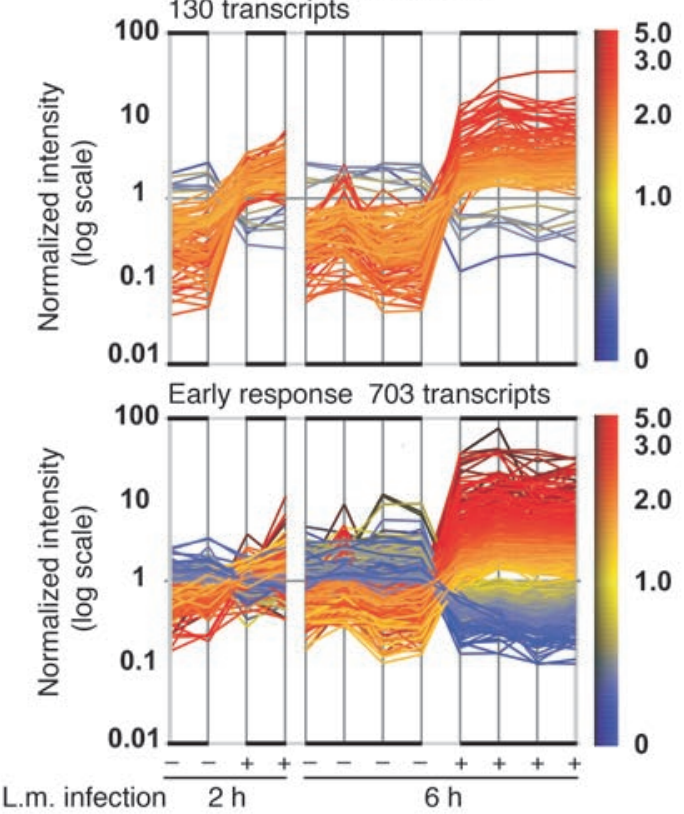

area between granulomas and DCs and macrophages within the ring wall prompted us to further characterize the phenotype of these ring-wall-forming cells.

One explanation for this spatial arrangement of antigen-presenting cells within the ring wall and the $\mathrm{T}$ cells outside the granulomas might be an inhibitory rather than immunostimulatory function of DCs and macrophages. Inhibitory DCs have been described earlier, and most recently the expression of IDO (gene symbol INDO), a key enzyme of tryptophan metabolism, has been associated with an inhibitory or tolerogenic DC phenotype (30). We therefore assessed IDO expression in listeriosis. As shown in Figure 1A, the great majority of cells within the cellular ring wall were strongly positive for IDO.

To further characterize the $\mathrm{IDO}^{+}$cells within the ring-wall structure, 2-color immunofluorescence was performed (Figure 1B). First, double-staining for S100 and CD68 confirmed that these 2 markers clearly distinguish between DCs and macrophages.

\section{Figure 2}

Overall transcriptional changes in human DCs infected with $L$. monocytogenes. (A) Unsupervised hierarchical clustering analysis of immDCs infected with L. monocytogenes (L.m.) for 2 hours or 6 hours or control (Con) mock-infected DCs, cultured at the same conditions for 2 hours or 6 hours. Affymetrix raw data were normalized using dChip, and a list of 1189 genes with high variability across the data set $(0.5<\mathrm{SD} /$ mean $<10)$ was used for hierarchical clustering in dChip. (B) Visualization using GeneSpring software of the most significantly changed genes after infection with L. monocytogenes. A total of 902 transcripts were defined with dChip as significantly changed at either time point; filtering criteria are described in detail in Methods. These significantly changed genes were ordered according to the temporal pattern of expression changes. Immediate-response genes are defined as being either up- or downregulated at the 2-hour time point but not at the 6-hour time point. Immediate-early response genes are characterized by upregulated or downregulated genes at both time points, and early response genes are regulated only at 6 hours. Expression values were normalized and color coded with upregulated genes in red and downregulated genes in blue. Each colored curve represents an expression pattern of a single gene; each vertical line represents 1 sample as indicated at the bottom of the figure. Detailed gene information is provided in Supplemental Table 2.

Staining with a specific antibody to the myeloid marker CD11c revealed that virtually all $\mathrm{S}_{100^{+}} \mathrm{DCs}$ were of myeloid origin (31). As expected, $\mathrm{CD}^{+} 8^{+}$macrophages were also $\mathrm{CD} 11 \mathrm{c}$ positive and were clearly smaller than $\mathrm{S} 100^{+} \mathrm{DCs}$. Next we allocated IDO expression to both cell populations. As can be seen in Figure 1B, basically all $\mathrm{S} 100^{+}$cells expressed significant levels of IDO whereas some smaller cells in between were $\mathrm{IDO}^{+} \mathrm{S} 100^{-}$. Double staining using IDO and $\mathrm{CD} 11 \mathrm{c}$ revealed that all IDO ${ }^{+}$cells were $\mathrm{CD} 11 \mathrm{c}^{+}$, suggesting that the small $\mathrm{S}^{100^{-}} \mathrm{IDO}^{+}$cells could be macrophages. Indeed, double staining of IDO and CD68 confirmed that macrophages also expressed IDO, although to a lesser extent than DCs. Moreover, some $\mathrm{CD}^{+} 8^{+}$macrophages did not express IDO. Colocalization of IDO with S100 or CD68 was clearly confirmed by confocal microscopy (Figure 1C). In summary, in addition to $\mathrm{CD} 68^{+}$macrophages, large myeloid $\mathrm{CD} 11 \mathrm{c}^{+} \mathrm{IDO}^{+} \mathrm{S} 100^{+} \mathrm{CD} 68^{-} \mathrm{DCs}$ are a major cell population contributing to the ring-wall structure of granulomas in human listeriosis.

Upregulation of IDO by immature DCs is an early but not immediate event. To examine the significance of in vivo IDO expression in DCs, we used the well-established in vitro system of monocytederived myeloid immDCs $(23,32,33)$ and assessed genome-wide transcriptional changes in immDCs 2 hours and 6 hours after infection with $L$. monocytogenes (for further details, see Supplemental Data and Supplemental Figure 2), using Affymetrix HG-U133A oligonucleotide microarrays. Unsupervised hierarchical clustering of samples based on the 1189 most variable transcripts (Supplemental Data) clearly distinguished infected immDCs from controls (Figure 2A). Within the group of infected immDC samples, the 2 time points were segregated, suggesting differential kinetics of transcriptional changes after infection with $L$. monocytogenes. We observed 3 patterns of transcriptional changes after infection similar to those found in murine bone-marrow-derived macrophages (34), which we termed immediate (changes only at 2 hours), immediate-early (changes at 2 and 6 hours), and early responses (changes at 6 hours) (Figure 2B, Supplemental Table 2, and Supplemental Data). IDO mRNA was undetectable in all control samples and after 2 hours of infection but significantly upregulated (37-fold, 

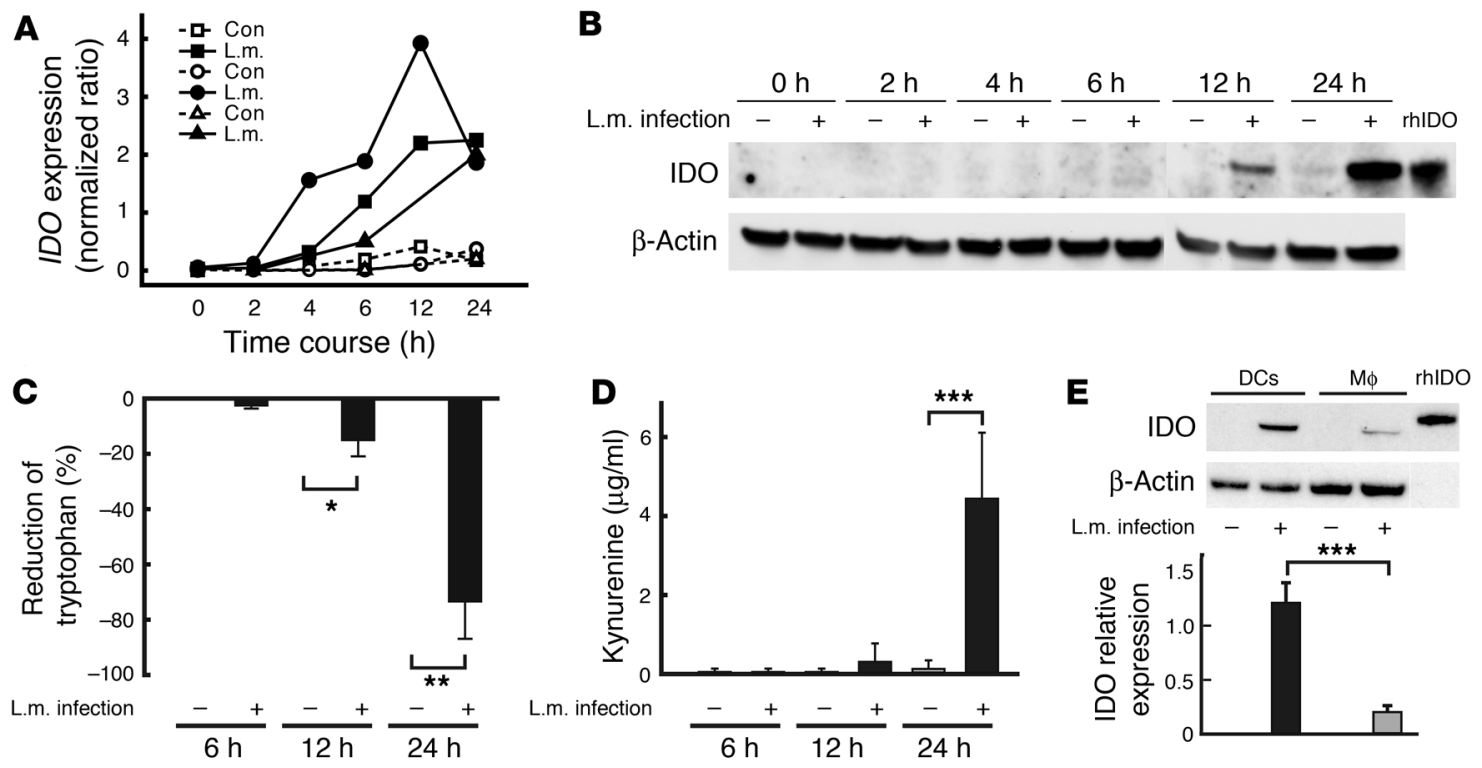

Figure 3

IDO is expressed on transcriptional and functional levels in human DCs infected with $L$. monocytogenes. (A) Time kinetic of IDO mRNA expression was assessed by quantitative real-time PCR. Expression of $\beta-2$ microglobulin (B2M) was used as a housekeeping gene control. Shown here are IDO expression profiles (normalized to B2M expression) in DC cultures derived from 3 different donors. Samples after $L$. monocytogenes infection are represented by filled symbols, the corresponding control samples by open symbols. (B) Protein expression of IDO and $\beta$-actin was assessed by immunoblotting after $L$. monocytogenes infection. Results of 1 representative experiment out of 6 are shown. rhIDO was used as a positive control. (C) Tryptophan depletion by enzymatically active IDO in cell supernatants was assessed by reverse-phase HPLC. Shown here is the reduction of tryptophan after 6,12 , or 24 hours in DC culture supernatants relative to tryptophan concentrations measured in DC medium alone. Mean $\pm \mathrm{SD}$ of 3 independent experiments is shown. Asterisks highlight statistically significant comparisons $\left({ }^{\star} P<0.05,{ }^{\star \star} P<0.00001\right)$. (D) Kynurenine accumulation at the same time points was assessed using a photometric assay. Shown here are mean \pm SD of 3 independent experiments. Asterisks highlight statistically significant comparison $\left({ }^{* * *} P<0.01\right)$. (E) Macrophages $(\mathrm{M} \phi)$ and DCs were differentiated from monocytes and infected with wild-type L. monocytogenes. After 24 hours, IDO protein expression was assessed by immunoblotting and analyzed quantitatively respective to $\beta$-actin expression. Representative Western blot and mean \pm SD of 3 independent experiments are shown. Asterisks highlight statistically significant comparison $\left({ }^{\star \star *} P<0.01\right)$.

$P<0.05) 6$ hours after infection (Supplemental Table 2). For the 6-hour time point, we performed significance analysis of microarrays (SAM) and prediction analysis of microarrays (PAM) $(35,36)$, demonstrating IDO to be the most significantly upregulated gene 6 hours after infection (SAM) and among the major predictors when applying PAM (data not shown). Transcriptional changes after L. monocytogenes infection were also observed for 2 other enzymes involved in tryptophan catabolism downstream of IDO, namely, kynurenine 3-monooxygenase (KMO) and kynureninase (KYNU) (Supplemental Table 2).

Next we assessed IDO upregulation during the first 24 hours after infection. Induction of IDO mRNA was detected as early as 4 hours after infection, peaking at 12-24 hours after infection (Figure $3 \mathrm{~A}$ ). Monitoring the expression of IDO protein using immunoblotting revealed that a very faint band was already visible at 6 hours after infection. The intensity of this band was greatly increased at the 24-hour time point (Figure 3B). Upregulation of IDO protein was accompanied by significant depletion of tryptophan from cell culture supernatants 12-24 hours after infection (Figure 3C). Moreover, tryptophan reduction in the cell culture medium was accompanied by the significant accumulation of its downstream metabolite kynurenine at 24 hours (Figure 3D). Early but not immediate induction of IDO suggested that IDO might be induced indirectly via intermediate signals triggered by L. monocytogenes infection.
To assess whether differential expression of IDO between $\mathrm{CD} 11 \mathrm{c}^{+} \mathrm{CD}_{68}^{+}$macrophages and $\mathrm{S} 100^{+} \mathrm{CD} 11 \mathrm{c}^{+} \mathrm{DCs}$ in vivo is also reflected by different levels of IDO in vitro, we generated macrophages and DCs from monocytes derived from 3 healthy individuals and infected these cells with L. monocytogenes. As shown in Figure 3E, IDO expression in the in vitro-generated DCs was also higher than in the in vitro-generated macrophages. This was also reflected by lower levels of IDO mRNA in macrophages (data not shown). Even with prolonged culturing (up to 48 hours), infected macrophages did not show enhanced IDO protein expression (data not shown).

Regulation of TNF- $\alpha$ and COX-2 precedes IDO expression after infection. Type I and II IFNs were previously described as potent inducers of IDO in macrophages (37), HeLa cells (38), and placentae (39). More recently, it was demonstrated that TNF- $\alpha$, together with prostaglandin $\mathrm{E}_{2}\left(\mathrm{PGE}_{2}\right)$, can also induce IDO in DCs $(33,40)$. We therefore evaluated transcriptional changes for IFNs, TNF- $\alpha$, COX-2 (encoded by PTGS2 and one of the key enzymes of PGE synthesis; ref. 41), and their receptors (Figure 4A and Supplemental Table 3). Transcripts for TNF- $\alpha$ (TNF) and COX-2 (PTGS2) were already significantly upregulated at 2 hours after infection and further increased by 6 hours after infection In contrast, transcripts coding for IFNs (IFNG, IFNB1) were only upregulated 6 hours after infection. Interestingly, among the respective receptors, only the $\mathrm{PGE}_{4}$ (EP4 or PTGER4), known to bind $\mathrm{PGE}_{2}$ on DCs (42), and TNFRSF1B (TNF-RII, p75 TNF receptor), which predominantly 
A

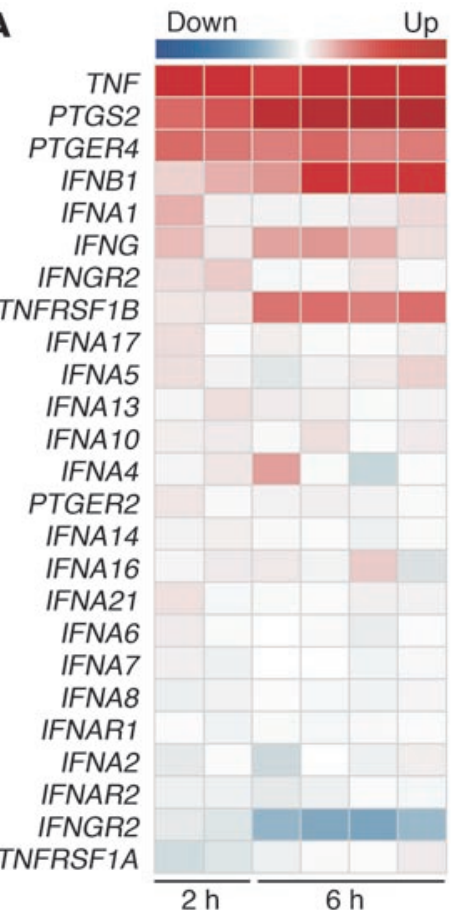

B

B

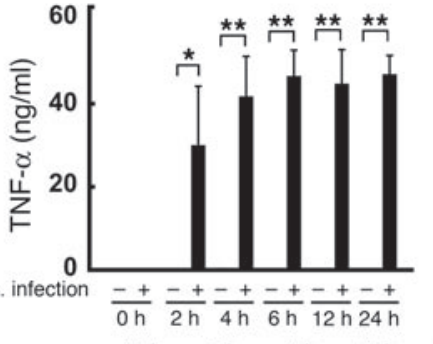

C

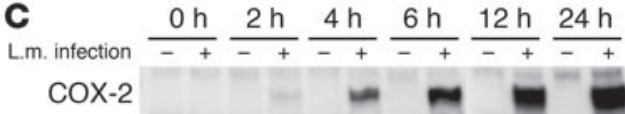

$\beta$-Actin

D

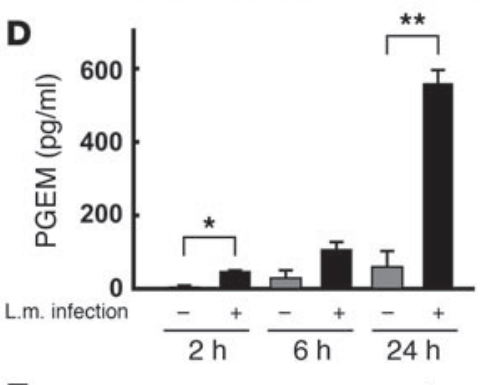

E

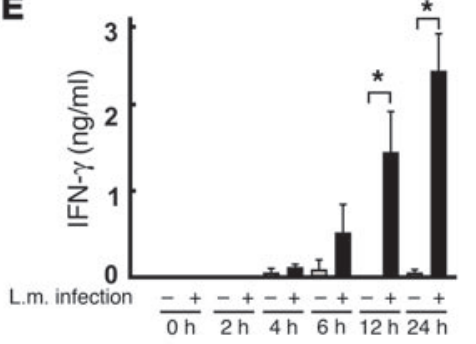

\section{Figure 4}

Regulation of genes and proteins shown to be associated with induction of IDO. (A) Heat map showing fold changes of gene transcription for type I and II IFNs, TNF- $\alpha$, and PTGS2 (COX-2) as well as the corresponding receptors. Fold changes were calculated for each individual sample pair (control DCs versus infected DCs from a matching donor at the respective time point) and color coded (blue, downregulated; white, unchanged; and red, upregulated genes); scale of fold changes ranged from -5.19 FC to +136.48 FC (Supplemental Table 3). (B) Protein expression of TNF- $\alpha$ in supernatants from immDCs either infected with $L$. monocytogenes $(+)$ or not infected (-) and subsequently cultured for up to 24 hours. Expression of TNF- $\alpha$ was assessed by ELISA. Shown here are mean \pm SD derived from 4 different donors. Asterisks highlight statistically significant comparisons $\left({ }^{*} P<0.05\right.$; $\left.{ }^{* *} P<0.01\right)$. (C) At the same time points as in B, DCs were harvested and subsequently lysed to assess protein expression of COX-2 and $\beta$-actin by immunoblotting. Results of 1 representative experiment out of 6 are shown. (D) To assess the function of COX-2 in DCs infected with $L$. monocytogenes (+) or control DCs (-), stable PGE metabolites (PGEM) were measured in DC supernatants by EIA at the indicated time points $(n=2)$. Asterisks highlight statistically significant comparisons $\left({ }^{* *} P<0.01\right)$. (E) Expression of IFN- $\gamma$ was assessed by ELISA. Shown here are mean \pm SD derived from 4 different donors. Asterisks highlight statistically significant comparisons $\left({ }^{\star} P<0.05\right)$. binds the transmembrane form of TNF (43), were significantly upregulated (Figure 4A and Supplemental Table 3).

Next we assessed protein expression of TNF- $\alpha$, IFNs, and COX-2 as well as $\mathrm{PGE}_{2}$ synthesis. While none of the molecules were expressed in control cultures, TNF- $\alpha$ was detected in substantial amounts in supernatants from infected immDCs as early as 2 hours after infection and further increased at later time points (up to $60 \mathrm{ng} / \mathrm{ml}$; Figure 4B). Similarly, COX-2 was already expressed at low levels 2 hours after infection (Figure 4C) and increased significantly by 6 hours after infection and by more than 10 -fold up to 24 hours after infection, as determined by quantitative analysis of immunoblots. Moreover, activation of COX-2 immediately after infection resulted in the early onset of $\mathrm{PGE}_{2}$ production, which was revealed by measuring PGE metabolites by enzymelinked immunoassay (EIA) in culture supernatants (Figure 4D). In contrast, IFN- $\gamma$ was measurable just above background levels at 6 hours after infection, and significant levels were only detected from 12 hours after infection onward (Figure 3E) whereas IFN- $\beta$ remained undetectable by ELISA in the supernatants throughout the culture period (data not shown). Interestingly, the in vitroinfected human macrophages secreted similar levels of TNF- $\alpha$ and IFN $-\gamma$ when compared to DCs (data not shown). These data clearly demonstrate that TNF- $\alpha$ and COX-2 precede the induction of IDO while a low level of IFN- $\gamma$ is detectable concomitantly with IDO at 6 hours with moderate upregulation at 24 hours after infection
Neutralization of TNF- $\alpha$ or IFN- $\gamma$ reduces expression and activity of IDO. The kinetics of TNF- $\alpha$ and $\mathrm{PGE}_{2}$ induction during L. monocytogenes infection suggested that they, along with IFN- $\gamma$, might be mediating the upregulation of $\operatorname{IDO}(33,40)$. To address this issue, we performed blocking experiments using a concentration range of the clinically used TNF- $\alpha$-neutralizing antibody infliximab (Remicade, $0.1-10 \mu \mathrm{g} / \mathrm{ml}$ ), the COX-2 inhibitor rofecoxib (Vioxx), and research-grade blocking antibodies for IFN- $\gamma$ and IFN- $\beta$ at neutralizing concentrations. Infliximab significantly impaired upregulation of IDO mRNA in a concentration-dependent manner after L. monocytogenes infection of immDCs (Figure 5A). Similarly, anti-IFN- $\gamma$ also inhibited upregulation of IDO mRNA while both rofecoxib and anti-IFN- $\beta$ had no effect. Interestingly, the combination of infliximab and anti-IFN- $\gamma$ antibodies did not further suppress $I D O$ upregulation (data not shown), suggesting that both factors might be involved in the same pathway. Similarly to transcriptional regulation, neutralization of TNF- $\alpha$ and IFN- $\gamma$, but not COX-2 or IFN- $\beta$, significantly inhibited the expression of IDO protein (Figure 5B). Furthermore, IDO enzymatic activity was also significantly decreased by TNF- $\alpha$ or IFN- $\gamma$ blockade, as was reflected by significantly reduced tryptophan depletion (data not shown) and kynurenine accumulation (Figure 5C) in cell culture supernatants. Analysis of TNF- $\alpha$ and IFN- $\gamma$ in culture supernatants revealed that TNF- $\alpha$ blockade also inhibited IFN- $\gamma$ upregulation in a dose-dependent manner (Figure 5D) while IFN- $\gamma$ blockade did 


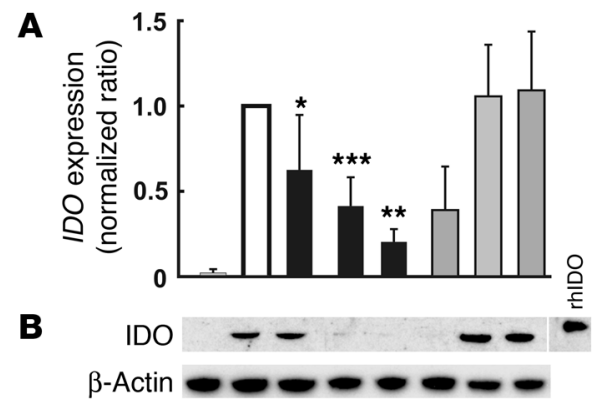

C

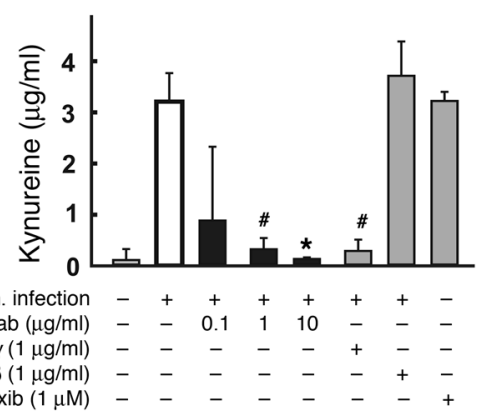

D

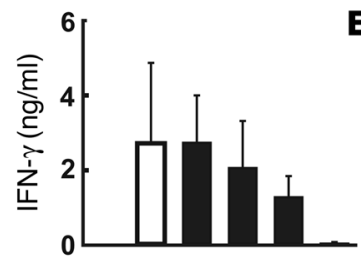

L.m. infection -+++++ Infliximab $(\mu \mathrm{g} / \mathrm{ml})-\left[\begin{array}{lllll}0 & 0.1 & 1 & 10 & -\end{array}\right.$ Anti-IFN- $\gamma(1 \mu \mathrm{g} / \mathrm{ml})-{ }_{-}-{ }_{-}+$

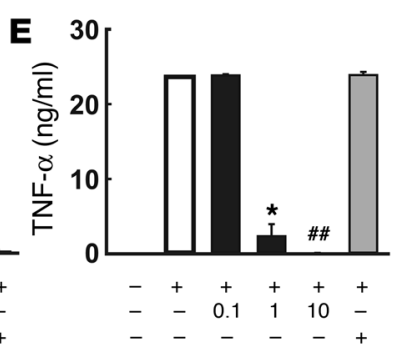

not impair TNF- $\alpha$ induction (Figure 5E), placing IFN- $\gamma$ induction downstream of TNF- $\alpha$ in human DCs after L. monocytogenes infection. Combining TNF- $\alpha$ blockade with COX-2 inhibition did not further reduce IDO function, suggesting that $\mathrm{PGE}_{2}$ is not required for induction of IDO activity after $L$. monocytogenes infection (data not shown). Neutralization of IFN- $\beta$ had no influence on either IDO expression or on its enzymatic activity (Figure 5).

Major virulence factors of $L$. monocytogenes are not required for induction of IDO. To determine which host-pathogen interactions might be critical for the induction of IDO in immDCs infected with listeria, we used 2 well-characterized avirulent $L$. monocytogenes mutants ( $\Delta$ bly and $\operatorname{prfA}$ ) as well as heat-killed (hk) bacteria. The $\Delta$ bly mutant does not allow escape of $L$. monocytogenes from phagosomes into the cytosol due to the defect of listeriolysin synthesis (44) while the prfA mutant lacks most virulence factors due to the impairment of the major listerial virulence regulator PrfA (45). Immunofluorescence microscopy of DCs infected with FITClabeled L. monocytogenes mutants and stained for F-actin revealed no typical actin condensation (up to 2 hours after infection), indicating that avirulent $L$. monocytogenes did not escape from the phagosome (data not shown). As an additional control, hk L. monocytogenes, which are phagocytosed by DCs but are quickly destroyed within phagosomes were used. As shown in Figure 6A, the 2 mutant listeria strains induced functionally active IDO, similar to the induction in wild-type L. monocytogenes. However, hk listeria did not induce detectable levels of IDO protein or its enzymatic activity. Likewise, COX-2 expression and $\mathrm{PGE}_{2}$ synthesis were strongly

\section{Figure 5}

Neutralization of TNF- $\alpha$ or IFN- $\gamma$ during $L$. monocytogenes infection downregulates IDO expression and enzymatic activity. immDCs were infected for 30 minutes at MOI 5, washed, and subsequently cultured for 24 hours in the absence or presence of neutralizing TNF- $\alpha$ antibody (infliximab, 0.1-10 $\mu \mathrm{g} / \mathrm{ml}$ ), anti-IFN- $\gamma$ antibody $(1 \mu \mathrm{g} / \mathrm{ml})$, anti-IFN- $\beta$ $(1 \mu \mathrm{g} / \mathrm{ml}$ ) or COX-2 inhibitor (rofecoxib, $1 \mu \mathrm{M})$. (A) IDO mRNA expression was assessed by quantitative real-time PCR. B2M was used as a housekeeping gene control; IDO expression of differentially treated DCs was normalized to the expression of infected, untreated DCs derived from the same donor. Mean \pm SD of at least 3 experiments per condition are shown. Asterisks highlight statistically significant comparisons $\left({ }^{\star} P<0.05,{ }^{* *} P<0.005,{ }^{* *} P<0.0005\right)$. (B) Protein expression of IDO was assessed by immunoblotting; rhIDO was used as a positive control. Data shown are derived from 1 representative experiment out of 3. (C) Kynurenine accumulation in the same cultures was assessed using a photometric assay. Shown here are mean \pm SD of at least 3 independent experiments. Legend underneath $\mathbf{C}$ also applies to $\mathbf{A}$ and B. Asterisks highlight statistically significant comparisons $\left({ }^{*} P<0.05\right.$, $\# P<0.01)$. Detection of IFN- $\gamma$ (D) and TNF- $\alpha$ (E) in supernatants from the same cultures described above. Shown here are mean \pm SD derived from at least 2 donors. Asterisks highlight statistically significant comparisons $\left({ }^{\star} P<0.05,{ }^{\#} P<0.0001\right)$.

induced by the 2 mutants but not by phagocytosed hk L. monocytogenes (Figure 6B). The lack of induction of IDO and COX-2 by hk bacteria was accompanied by only low-level secretion of TNF- $\alpha$ at all time points measured (Figure 6C). Analysis of genome-wide transcriptional changes over time further demonstrated that hk listeria did not lead to a sustained response of immDCs (Figure 6D). In summary, while IDO is induced by viable L. monocytogenes mutants lacking well-described virulence factors, challenge of DCs with hk listeria does not upregulate TNF- $\alpha$, COX-2, and IDO and is accompanied by an overall limited transcriptional response.

To elucidate potential factors expressed by viable listeria responsible for the induction of IDO, we postulated such a factor to be involved in early host-pathogen interactions between bacterial surface proteins and the pattern recognition receptors of DCs, such as TLR. LPS, a gram-negative bacteria-derived TLR ligand, has recently been shown to be involved in upregulation of IDO in myeloid DCs (40); however, gram-positive listeria do not express LPS. The cell wall of listeria consists mostly of lipoteichoic acid (LTA) (46, 47), which utilizes TLR2 as a signaling receptor (48). Interestingly, expression of TLR2 on DCs was significantly upregulated during listeria infection (Supplemental Table 2). We therefore hypothesized that LTA might be involved in the induction of IDO. Assessment of IDO expression in DCs stimulated with highly purified LTA derived from L. monocytogenes revealed that LTA can indeed induce IDO expression in DCs (Figure 6E).

Ring-wall formation containing $I D O^{+} D C s$ in other diseases. To assess whether IDO-expressing DCs might also play a role in other granu- 

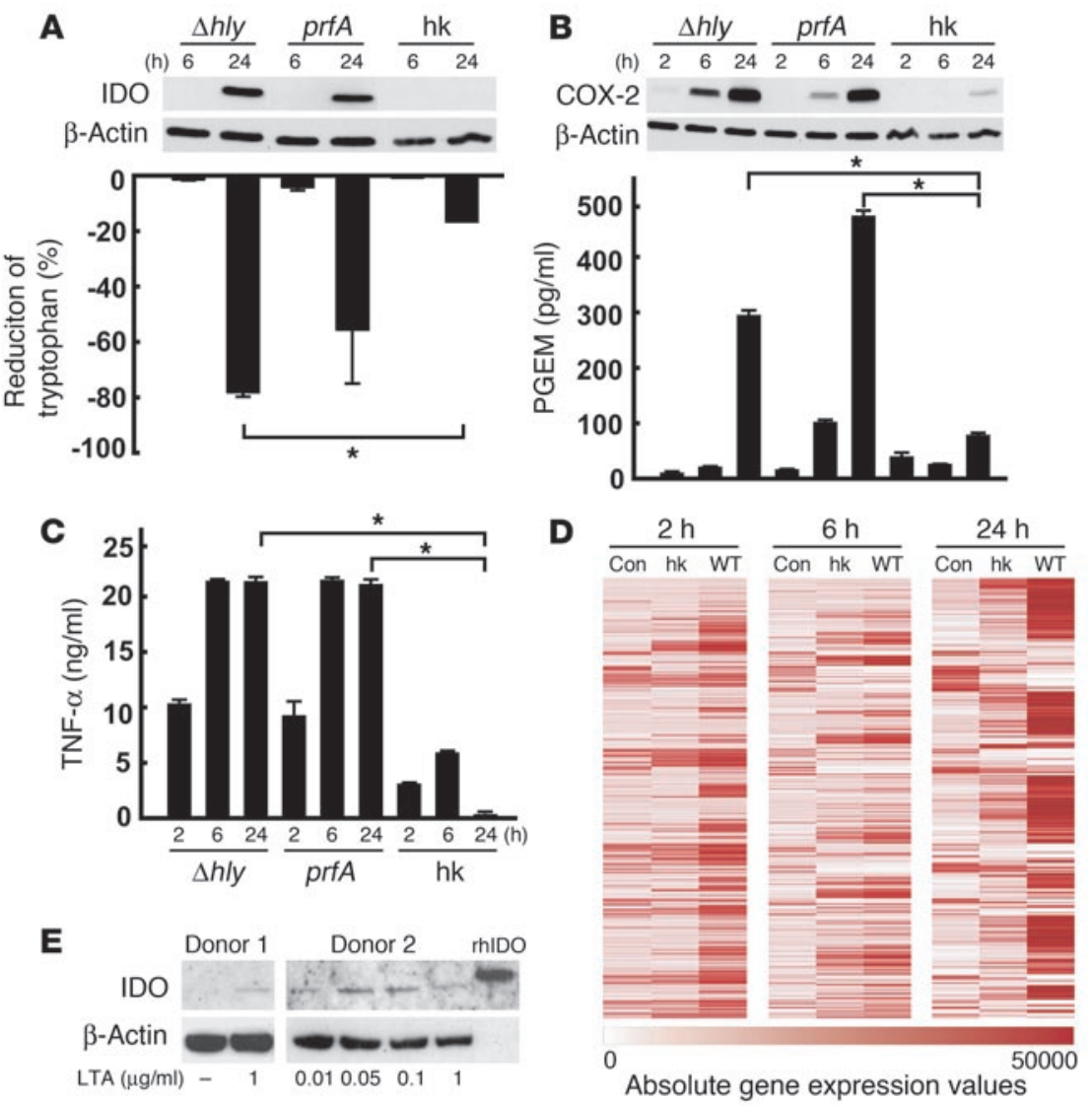

\section{Figure 6}

Influence of $L$. monocytogenes virulence factors on IDO induction. immDCs were either infected with the listeria mutants $\Delta h l y$ or prfA or incubated with hk L. monocytogenes for 30 minutes, washed, and subsequently cultured for 2, 6, or 24 hours Alternatively, DCs were treated with purified LTA derived from L. monocytogenes and cultured for 72 hours. Cells and supernatants were then harvested to assess (A) IDO protein expression and tryptophan levels, (B) COX-2 protein expression and PGE metabolite levels, and (C) TNF- $\alpha$ concentration. Mean \pm SD from 2 experiments are shown. Asterisk highlights statistically significant comparison $\left({ }^{\star} P<0.05\right)$. Immunoblots are representative of 2 independent experiments. (D) A heat map illustrating the kinetics of gene expression in immDCs treated with hk $L$. monocytogenes or infected with virulent $L$. monocytogenes (WT) and corresponding mock-infected controls on a Sentrix Human-6 Expression BeadChip array. Examination of genes showing significant differences in expression levels between control and listeria-infected DCs at 1 of the 3 time points (fold change $>2$; absolute difference in signal intensity > 100) yielded 1,444 candidate genes. Absolute expression values of these gene transcripts in all 3 cell subsets were color coded (white, low expression; dark red; high expression); scale of expression values ranged from 0 to 50,000 . (E) IDO protein expression in human DCs was assessed by immunoblotting after 72 hours of LTA treatment at indicated concentrations; $\beta$-actin was used as loading control and rhIDO as a positive control. Results of 2 representative experiments are shown.

lomatous diseases, we analyzed lymph node samples from patients with granuloma-associated diseases, such as catscratch disease (CSD), caused by Bartonella henselae, tuberculosis, and sarcoidosis, and compared those with lymph node samples from patients with infectious diseases lacking granulomas, including malakoplakia, mycobacterial histiocytosis, and Whipple disease (for detailed description, see Supplemental Data and Supplemental Figures 3 and 4). The most closely related findings for cells expressing significant amounts of IDO within the ring-wall structure were obtained in CSD. Similar to listeriosis, CSD is histologically characterized by suppurative granulomas. There were fewer DCs in CSD as compared with listeriosis; however, most of the DCs were also positive for IDO (Supplemental Figure 3). In tuberculosis and sarcoidosis, $\mathrm{IDO}^{+}$cells surrounding granulomas were also detectable although clearly at lower quantities. In contrast, $\mathrm{IDO}^{+}$ cells could not be detected in any of the nongranulomatous diseases, further supporting a substantial role of $\mathrm{IDO}^{+}$cells in human granulomas (Supplemental Figure 4).

\section{Discussion}

Formation of abscesses or granulomas is an important host reaction to control pathogens, especially when the latter cannot be eliminated by an effective adaptive immune response. The cellular components and molecular mechanisms involved are strongly dependent on the particular pathogen and the host responsiveness. Most often, macrophages and $T$ cells have been associated with ring-wall formation surrounding such containment structures (1-3). Here we demonstrate that DCs, along with macrophages, are a major cell type found in ring walls of suppurative granulomas in human listeriosis while $\mathrm{T}$ and B cells are virtually absent within these structures. This strongly suggests an inhibitory mechanism that is provided by the cells within the ring wall, thereby prohibiting access of $\mathrm{T}$ and $\mathrm{B}$ cells to the granulomas. Indeed, by immunohistochemistry, we identified the majority of cells within the ring wall as expressing IDO, an enzyme reportedly associated with strong inhibitory effects on $\mathrm{T}$ cell activation $(30,33,49)$. IDO was found by transcriptional profiling and quantitative real-time RT-PCR to be the most significantly upregulated gene in human DCs within 4-6 hours after infection with $L$. monocytogenes. Transcriptional upregulation was followed by a strong upregulation of functional IDO at the protein level as early as 12 hours after infection, which resulted in significant tryptophan depletion and kynurenine accumulation in supernatants of infected DCs. Furthermore, we established that endogenous TNF- $\alpha$ and IFN- $\gamma$, which are secreted by the infected DCs, are upstream of IDO induction. Therefore, IDO induction seems to be a strictly cell-autonomous response of DCs as a consequence of $L$. monocytogenes infection since no other exogenous cells or signals other than infection were necessary. In contrast with the uptake of hk listeria, infection with avirulent mutants of L. monocytogenes also induced IDO expression in DCs, suggesting that the induction of IDO by listeria appears to be independent of currently known virulence factors but requires viable bacteria. Here we could identify LTA at least as 1 Listeria-derived component capable of inducing IDO in DCs. By assessing other infectious diseases and sarcoidosis, a noninfectious granulomatous disease, we 
demonstrate that $\mathrm{IDO}^{+}$DCs are associated with granulomatous diseases but absent in nongranulomatous infectious diseases.

Only recently, some of the cells and mechanisms involved in abscess formation by other pathogens, e.g., Staphylococcus aureus and Bacillus fragilis, were characterized (50). So far, formation of structural containments for bacteria has mainly been attributed to granulocytes, macrophages, and $\mathrm{T}$ cells $(1,51,52)$. T cells activate macrophages and polymorphonuclear cells, which then adhere to locally activated mesothelium, a requirement for the initiation of abscess formation (50). In acute murine listeriosis, granulocytes and macrophages play a major role in abscess formation in the liver, where DCs were shown to be absent (7). In contrast, we show here in advanced-stage human listeriosis that DCs, together with macrophages, are a major component of the ring-wall structure of granulomas while granulocytes are mainly found in the center of granulomas. This structural contribution itself suggests an unexpected and new function of DCs at the forefront of defense against intracellular pathogens. Differences between murine models of listeriosis and our findings in human listeriosis suggest that this foodborne disease has a rather different pathology in systemically infected mice, probably due to the different routes of infection. With the emergence of new animal models of listeriosis (53), however, it will become possible to study the role of DCs in the pathophysiology of human chronic listeria infection.

The strong enrichment of DCs within the ring wall and the almost complete absence of $\mathrm{T}$ cells in this area were striking. We postulated that prohibiting $\mathrm{T}$ cells to enter these ring-wall structures would require efficient inhibitory signals. Recent findings clearly demonstrated that tolerogenic or inhibitory DCs express IDO $(33,54,55)$. In fact, $\mathrm{S} 100^{+} \mathrm{CD} 11 \mathrm{c}^{+} \mathrm{DCs}$ and also CD $68^{+}$macrophages within the ring-wall structure expressed substantial amounts of this immunoregulatory enzyme (Figure 1A). Interestingly, although in vitro-generated macrophages produced comparable amounts of TNF- $\alpha$ and IFN- $\gamma$, they did not induce IDO to as high levels as seen in DCs, both in vivo and in vitro. There has been debate about the role of tryptophan depletion by $\mathrm{IDO}^{+} \mathrm{DCs}$ for $\mathrm{T}$ cell inhibition since DCs are normally dispersed in rather low frequencies throughout lymphoid tissues, and therefore a significant gradient of tryptophan and an accumulation of its toxic metabolite kynurenine might actually not be apparent (56). However, a dense wall of $\mathrm{IDO}^{+}$cells surrounding granulomas (Figure 1A) could result in local consumption of tryptophan and accumulation of kynurenine, leading to $\mathrm{T}$ cell inhibition in vivo, as has been shown previously by others and by us for human DCs in vitro $(33,40,55)$.

The major function of granulomatous structures is the containment of otherwise uncontrollable pathogens. Therefore, destruction of granulomas by cytotoxic T cells would be counterproductive for the survival of the host $(1,57)$. Clear evidence about the destructive role of $\mathrm{T}$ cells on established granulomas stem from experiments in $\mathrm{TNF}^{-/-}$mice (58) infected with mycobacteria. These mice quickly die from respiratory failure after destruction of bacteria-induced granulomas. Destruction of granulomas is accompanied by an uncontrolled type 1 immune syndrome characterized by expansion of activated IFN- $\gamma$-producing T cells. The immune response leading to granuloma destruction and bacterial dissemination in these mice is prevented by depletion of T cells, which prolongs survival of the animals (58).

As outlined above, the formation and maintenance of granulomas is TNF- $\alpha$ dependent (58-61). However, events downstream of TNF- $\alpha$ signaling leading to the maintenance of granulomas are still not well characterized. In DCs infected with L. monocytogenes, significant TNF- $\alpha$ production is a major element of the cellular response. Using different neutralizing TNF- $\alpha$ antibodies, including the clinically used antibody infliximab, we demonstrate that expression and function of IDO after L. monocytogenes infection depends on TNF- $\alpha$ expression. This places IDO downstream of TNF- $\alpha$ in L. monocytogenes infection. Localized IDO expression by cells within granulomas might be one of the mechanisms keeping $\mathrm{T}$ cells at bay. In patients with rheumatoid arthritis treated with TNF- $\alpha$-neutralizing therapy using infliximab or etanercept (Enbrel), fulminant exacerbation of tuberculosis, listeriosis, and other granulomatous infections has recently been recognized as a severe adverse event (62-65). Interestingly, in patients with Crohn disease, characterized by high local expression of IDO, treatment with infliximab led to reduced IDO expression (66). Hence, inhibition of immunoregulatory mechanisms, such as tryptophan catabolism by IDO, as a consequence of TNF- $\alpha$-neutralizing therapy are likely to play an important role during disaggregation of preexisting granulomas in tuberculosis and listeriosis.

Taken together, our findings in human listeriosis suggest a new function of DCs. In addition to their important role for the induction of specific immunity, DCs seem to be a major contributor of the cellular components of suppurative granulomas. Moreover, the expression of the immunoregulatory enzyme IDO by these DCs strongly suggests that not only structural but also metabolic mechanisms are involved in the granulomatous containment of intracellular pathogens, such as L. monocytogenes or $B$. henselae, in humans. Our findings also warrant further exploration of the in vivo role of DCs during infection with L. monocytogenes and other life-threatening intracellular pathogens, using genetically engineered and clinically relevant animal models, once these become available (53).

\section{Methods}

Blood and lymph node samples. Blood samples were collected from healthy blood donors at the Center for Transfusion Medicine (University of Cologne, Cologne, Germany) after informed written consent was obtained. Lymph node specimens were acquired from the pathology archive of the Institute for Pathology (University of Cologne). For these experiments, approval was obtained from the University of Cologne Institutional Review Board.

Histochemistry. Lymph node specimens from 3 patients with clinically and serologically confirmed listeriosis were available from the local pathology archive. Conventional histological staining (H\&E, van Gieson, PAS, and Ziehl-Neelsen) was performed according to standard procedures (IHC World; http://www.ihcworld.com) using paraffin-embedded tissue samples. For immunohistochemistry, CD3, CD15, CD20, CD68, and S100 mAbs were obtained from Dako; IDO polyclonal Ab from AbD Serotec; and $\mathrm{CD} 11 \mathrm{c}$ from Novocastra. For double-labeling fluorescence microscopy, CD68-FITC was obtained from Dako. Anti-mouse Cy2, anti-sheep $\mathrm{Cy} 3$, anti-rabbit $\mathrm{Cy} 2$ and anti-rabbit $\mathrm{Cy} 3$ were obtained from Jackson ImmunoResearch Laboratories Inc. Slides were evaluated with an ARISTOPLAN microscope (Leitz). An appropriate triple-band pass filter set (Leica) was selected for visualization of Cy2, Cy3, and DAPI labeling with fluorescence excitation/emission maxima (nm) as follows: 490/525, 540/550, and $365 / 480$. To assure the colocalization of IDO with $\mathrm{S}_{100}{ }^{+}$or $\mathrm{CD} 8^{+}$cells, confocal microscopy with Olympus FluoView FV1000 Confocal Microscope (Olympus) was performed.

Ultrastructural analysis. Ultrastructural analysis to ascertain diagnosis of malakoplakia was performed on renal biopsies following standard protocols. Sections were analyzed with a Zeiss EM 902A (Zeiss). 
Verification of pathogens. Genomic DNA of L. monocytogenes, M. tuberculosis, and $B$. henselae was identified by PCR. Paraffin wax-embedded lymph node sections were dewaxed in xylene $\left(65^{\circ} \mathrm{C}, 20 \mathrm{~min}\right)$, washed in $100 \%$ ethanol, and then lysed in proteinase $\mathrm{K}$ buffer $(500 \mu \mathrm{g} / \mathrm{ml}$ proteinase $\mathrm{K}$ [Invitrogen], 50 $\mathrm{mM}$ Tris/HCl, $\mathrm{pH}$ 7.4, and $5 \mathrm{mM}$ EDTA, pH 8). Nucleic acids were extracted by phenol/chloroform and subsequently precipitated with sodium acetate and isopropanol. Primers used are listed in Supplemental Table 1.

Bacteria. The L.monocytogenes wild-type strain EGD and isogenic deletion mutant strains $\Delta b l y$ and $\operatorname{prfA}(44,45)$ were cultured in brain-heart infusion (BHI) until they reached log phase. After harvesting, listeria were incubated with $2 \mathrm{mg} / \mathrm{ml}$ of FITC (Sigma-Aldrich) for 1 hour at room temperature and subsequently washed with $5 \mu \mathrm{M}$ EDTA in PBS. A stock of FITC-labeled listeria was frozen at $-80^{\circ} \mathrm{C}$ in PBS supplemented with $10 \%$ DMSO until further use. Listeria (hk) were obtained by incubating wildtype bacteria in $\mathrm{PBS}\left(65^{\circ} \mathrm{C}, 1\right.$ hour). Viability of listeria was controlled by CFU assay on blood agar.

Culture of DCs and macrophages. DCs were generated from blood-derived monocytes as previously described (33). Briefly, PBMCs were isolated from buffy coats by Ficoll-Paque density-gradient centrifugation, and monocytes were subsequently enriched by CD14 MicroBeads (Miltenyi Biotec). Monocytes (purity $95 \%-98 \%$, as assessed by FACS) were cultured in serumfree conditions with GM-CSF and IL-4 following previously established protocols (33). Purity of DCs was determined by flow cytometry analysis of lineage and differentiation markers and viability assessed by propidium iodide staining. The immDCs were further processed only if all cells were negative for CD3, CD19, or CD83; low-positive or negative for CD14; and highly positive for CD11c, CD13, CD33, HLA-DR, CD206, and DC-SIGN. For some experiments, DCs were matured with anti-CD40 antibody and TNF- $\alpha$, as previously described (33). Macrophages were generated from monocytes in RPMI-1640 (Invitrogen) and supplemented with 10\% FCS (Invitrogen) and $500 \mathrm{U} / \mathrm{ml} \mathrm{GM-CSF}$, as described elsewhere $(67,68)$. The typical phenotype of macrophages after 7 days of culture was assured by surface staining with CD14, CD11c, and CD11b (all markers positive) and HLA-DR (low-positive) and intracellular staining with CD68 (positive).

Infection of DCs with L. monocytogenes. Monocytes and DCs $\left(1 \times 10^{6}\right.$ cells) were infected with FITC-labeled listeria (MOI 1-50, 5-30 min) in $1 \mathrm{ml}$ HBSS buffer ( $1 \%$ autologous plasma or $5 \%$ human serum from plasma type AB [Sigma-Aldrich]) as described previously (69). After 30 minutes of incubation, cells were washed with HBSS buffer followed by passage through a $30 \%$ sucrose layer, thereby avoiding transfer of nonphagocytosed extracellular bacteria to the subsequent cell culture. Infected and washed DCs were cultured in fresh DC medium $\left(2 \times 10^{6}\right.$ cells $\left./ \mathrm{ml}\right)$. Infection efficiency was assessed by flow cytometry and subcellular localization of phagocytosed bacteria by the double-fluorescence method $(70,71)$. Microscopy was performed with an Olympus FluoView FV1000 Confocal Microscope. Experiments were conducted without addition of antibiotics, except for some prolonged cultures (24 hours, gentamycin, $50 \mu \mathrm{g} / \mathrm{ml}$, added 1 hour after infection; Invitrogen). In some experiments, neutralizing antibodies were added to DC cultures immediately after infection: $1 \mu \mathrm{g} / \mathrm{ml} \mathrm{mAb}$ to IFN- $\beta$ (PBS-03; Abcam), 0.1-1 $\mu \mathrm{g} / \mathrm{ml} \mathrm{mAb}$ to IFN- $\gamma$ (B27; BD Biosciences - Pharmingen), $20 \mu \mathrm{g} / \mathrm{ml} \mathrm{mAb}$ to TNF- $\alpha$ (MAb1; BD Biosciences - Pharmingen), or the clinically used TNF- $\alpha$ neutralizing antibody infliximab $(0.001-10 \mu \mathrm{g} / \mathrm{ml})$. The COX-2 inhibitor rofecoxib (a kind gift of K. Schrör and J. Meyer-Kirchrath, Institute for Pharmacology and Clinical Pharmacology, University of Düsseldorf, Düsseldorf, Germany) was used at 0.1 to $10 \mu \mathrm{M}$. All inhibitors were previously tested in standard systems (ELISA, EIA, immunoblotting) and were found to be specifically inhibitory for their respective targets.

Purification of LTA. LTA from wild-type L. monocytogenes was prepared and purified as described elsewhere $(72,73)$. Endotoxin contamination of LTA was assessed by the kinetic limulus amoebocyte lysate assay (Charles River Laboratories). Purified LTA (endotoxin $<0.5 \mathrm{EU} / \mathrm{mg}$ ) was used in a concentration range of $0.01-10 \mu \mathrm{g} / \mathrm{ml}$.

RNA preparation, microarray bybridization, and data processing. DCs were harvested 2, 6, and 24 hours after infection, lysed in TRIzOL reagent (Invitrogen), and stored at $-80^{\circ} \mathrm{C}$ until further processing. Target preparation and array hybridization (HG-U133A, Affymetrix; and Sentrix Human-6 Expression BeadChip array; Illumina) were performed as described previously $(74,75)$. All arrays were normalized with dChip 2005 at probe intensity level against the array with overall median signal intensity. The following filtering criteria were used for selection of differentially expressed genes: lower boundary of the $90 \%$ confidence interval of the fold change greater than 2 , absolute difference in signal intensity between group means greater than 100 , and percentage of present calls of probe sets greater than or equal to 50 . For data analysis and visualization, R software version 2.2.1 (http://www.r-project. org) (76), GeneSpring 7.2 (Agilent Technologies), and Mayday 2.0 (http:// www.zbit.uni-tuebingen.de/pas/mayday) were used (77).

ELISA and EIA. IFN- $\gamma$, TNF- $\alpha$, IFN- $\beta$, and $\mathrm{PGE}_{2}$ metabolites in supernatants were measured by human IFN- $\gamma$ and TNF- $\alpha$ Eli-Pair kits (Diaclone Research), Human Interferon Beta ELISA Kit (R\&D Systems), and Prostaglandin E Metabolite EIA Kit (Cayman Chemical), respectively, according to manufacturers' instructions.

Quantitative real-time PCR. Quantitative real-time PCR was performed with a LightCycler TaqMan Master kit and a Universal ProbeLibrary Assay on a LightCycler 1.3 and analyzed by LightCycler 3 and RelQuant software (version 1.0; Roche Diagnostics) using a calibrator-normalized relative quantification approach. Relative quantification was based on $\beta$ - 2 microglobulin expression. Primers used are listed in Supplemental Table 1.

Immunoblot analysis. Immunoblot analysis was performed as previously described $(33,78)$. The following antibodies were used: monoclonal (Chemicon International) or polyclonal anti-IDO antibody (AbD Serotec); polyclonal anti-COX-2 antibody (IBL); and monoclonal $\beta$-actin antibody (Sigma-Aldrich). Recombinant human IDO (rhIDO) served as positive control.

Assessment of tryptophan and kynurenine concentration in supernatants. Supernatants from DC cultures were collected 6, 12, and 24 hours after infection, diluted 1:30 in double-distilled water, and assessed for tryptophan concentrations by HPLC as previously described $(33,49)$. Tryptophan medium concentration was $5 \mu \mathrm{g} / \mathrm{ml}$ for CellGro DC medium (CellGenix) (as measured by HPLC). Kynurenine was assessed using a spectrophotometric assay as previously described $(40,49)$. Supernatants were mixed with $30 \%$ trichloroacetic acid (2:1), vortexed, and centrifuged at 8,000 $\mathrm{g}$ for 5 minutes. Subsequently, $75 \mu \mathrm{l}$ of this mixture was added to an equal volume of Ehrlich reagent (100 mg p-dimethylbenzaldehyde, $5 \mathrm{ml}$ glacial acetic acid) in a 96-well microtiter plate. Samples (in triplicate) were run against a standard curve of defined kynurenine concentrations $(0-100 \mu \mathrm{g} / \mathrm{ml})$. Optical density was measured using a Medgenix 400 AT microplate reader (SLT Instruments) at $492 \mathrm{~nm}$ within 10 minutes.

Statistics. Statistical significance was calculated by a 2-sample 2-tailed Student's $t$ test (R software version 2.2.1). Comparisons were considered statistically significant at $P<0.05$.

\section{Acknowledgments}

We are grateful to all blood donors for donating blood for this study. We thank Birgit Gathof from the Center for Transfusion Medicine for providing us with peripheral blood products. We also thank Alexander Poyarkov for helpful discussion during the preparation of this manuscript and Thomas Quast and Waldemar Kolanus for help with confocal microscopy. We thank Nektaria Papadopoulou for preparation of rhIDO and K. Schrör and 
J. Meyer-Kirchrath for providing rofecoxib. We thank Martina Bessler, Madlen Strauß, Mirela Stecki, Silke Kummer, and Julia Claasen for technical assistance. This work was supported by a Sofja Kovalevskaja Award from the Alexander von Humboldt Foundation (to J.L. Schultze), a Köln Fortune grant (to J.L. Schultze), and grants from the German Bundesministerium für Bildung and Forschung (NGFN 01GS0111 to T. Chakraborty and NGFN N1K3-S24T27 to J.L. Schultze) and the Deutsche Forschungsgemeinschaft (SFB589 to C. Wickenhauser and SFB670 to M. Krönke and O. Utermöhlen) and in part by a Maria-Pesch Stiftung grant (to T. Saric).

1. Kaufmann, S.H. 1993. Immunity to intracellular bacteria. Annu. Rev. Immunol. 11:129-163.

2. Gordon, S. 2003. Alternative activation of macrophages. Nat. Rev. Immunol. 3:23-35.

3. Pamer, E.G. 2004. Immune responses to Listeria monocytogenes. Nat. Rev. Immunol. 4:812-823.

4. Unanue, E.R. 1997. Studies in listeriosis show the strong symbiosis between the innate cellular system and the T-cell response. Immunol. Rev. 158:11-25.

5. Portnoy, D.A., Auerbuch, V., and Glomski, I.J. 2002. The cell biology of Listeria monocytogenes infection: the intersection of bacterial pathogenesis and cell-mediated immunity. J. Cell Biol. 158:409-414.

6. Drevets, D.A., et al. 2004. The Ly-6Chigh monocyte subpopulation transports Listeria monocytogenes into the brain during systemic infection of mice. J. Immunol. 172:4418-4424.

7. Torres, D., et al. 2004. Toll-like receptor 2 is required for optimal control of Listeria monocytogenes infection. Infect. Immun. 72:2131-2139.

8. Czuprynski, C.J., Henson, P.M., and Campbell, P.A. 1984. Killing of Listeria monocytogenes by inflammatory neutrophils and mononuclear phagocytes from immune and nonimmune mice. J. Leukoc. Biol. 35:193-208.

9. Cossart, P., and Sansonetti, P.J. 2004. Bacterial invasion: the paradigms of enteroinvasive pathogens. Science. 304:242-248.

10. Dussurget, O., Pizarro-Cerda, J., and Cossart, P. 2004. Molecular determinants of Listeria monocytogenes virulence. Annu. Rev. Microbiol. 58:587-610.

11. Lecuit, M., et al. 1999. A single amino acid in E-cadherin responsible for host specificity towards the human pathogen Listeria monocytogenes. $E M B O$ J. 18:3956-3963.

12. Lecuit, M., et al. 2001. A transgenic model for listeriosis: role of internalin in crossing the intestinal barrier. Science. 292:1722-1725.

13. Southwick, F.S., and Purich, D.L. 1996. Intracellular pathogenesis of listeriosis. N. Engl. J. Med. 334:770-776.

14. Vazquez-Boland, J.A., et al. 2001. Listeria pathogenesis and molecular virulence determinants. Clin. Microbiol. Rev. 14:584-640.

15. Pron, B., et al. 2001. Dendritic cells are early cellular targets of Listeria monocytogenes after intestinal delivery and are involved in bacterial spread in the host. Cell. Microbiol. 3:331-340.

16. Edelson, B.T., and Unanue, E.R. 2000. Immunity to Listeria infection. Curr. Opin. Immunol. 12:425-431.

17. Feng, H., et al. 2005. Listeria-infected myeloid dendritic cells produce IFN-beta, priming T cell activation. J. Immunol. 175:421-432.

18. Muraille, E., et al. 2005. Distinct in vivo dendritic cell activation by live versus killed Listeria monocytogenes. Eur. J. Immunol. 35:1463-1471.

19. Harrington-Fowler, L., and Wilder, M.S. 1982. Fate of Listeria monocytogenes in murine peritoneal macrophage subpopulations. Infect. Immun. 35:124-132.

20. Gervais, F., Morris-Hooke, A., Tran, T.A., and Skamene, E. 1986. Analysis of macrophage bactericidal function in genetically resistant and susceptible
Received for publication May 4, 2006, and accepted in revised form September 19, 2006.

Address correspondence to: Joachim L. Schultze, Molekulare Tumorbiologie und Tumorimmunologie, Klinik I für Innere Medizin, Universitätsklinikum Köln, Kerpener Strasse 62/Haus 16 UG, 50924 Köln, Germany. Phone: 49-221-478-4489; Fax: 49-221-47886095; E-mail: Joachim.Schultze@uk-koeln.de.

Alexey Popov, Zeinab Abdullah, and Claudia Wickenhauser contributed equally to this work. mice by using the temperature-sensitive mutant of Listeria monocytogenes. Infect. Immun. 54:315-321.

21. Serbina, N.V., Salazar-Mather, T.P., Biron, C.A., Kuziel, W.A., and Pamer, E.G. 2003. TNF/iNOSproducing dendritic cells mediate innate immune defense against bacterial infection. Immunity. 19:59-70.

22. Kolb-Maurer, A., et al. 2000. Listeria monocytogenes-infected human dendritic cells: uptake and host cell response. Infect. Immun. 68:3680-3688.

23. Paschen, A., et al. 2000. Human dendritic cells infected by Listeria monocytogenes: induction of maturation, requirements for phagolysosomal escape and antigen presentation capacity. Eur. J. Immunol. 30:3447-3456.

24. Mielke, M.E., Peters, C., and Hahn, H. 1997. Cytokines in the induction and expression of T-cell-mediated granuloma formation and protection in the murine model of listeriosis. Immunol. Rev. 158:79-93.

25. Rogers, H.W., and Unanue, E.R. 1993. Neutrophils are involved in acute, nonspecific resistance to Listeria monocytogenes in mice. Infect. Immun. 61:5090-5096.

26. Conlan, J.W., and North, R.J. 1994. Neutrophils are essential for early anti-Listeria defense in the liver, but not in the spleen or peritoneal cavity, as revealed by a granulocyte-depleting monoclonal antibody. J. Exp. Med. 179:259-268.

27. Howie, A.J., Brown, G., Fisher, A.G., and Khan, M. 1984. Widespread distribution in human tissues of an antigenic determinant of granulocytes. J. Clin. Pathol. 37:555-559.

28. Lau, S.K., Chu, P.G., and Weiss, L.M. 2004. CD163: a specific marker of macrophages in paraffinembedded tissue samples. Am. J. Clin. Pathol. 122:794-801.

29. Perez, L., et al. 2005. Comparative analysis of CD1a, S-100, CD83, and CD11c human dendritic cells in normal, premalignant, and malignant tissues. Histol. Histopathol. 20:1165-1172.

30. Mellor, A.L., and Munn, D.H. 2004. IDO expression by dendritic cells: tolerance and tryptophan catabolism. Nat. Rev. Immunol. 4:762-774.

31. Kohrgruber, N., et al. 1999. Survival, maturation, and function of CD11c- and CD11 $\mathrm{c}^{+}$peripheral blood dendritic cells are differentially regulated by cytokines. J. Immunol. 163:3250-3259.

32. Sallusto, F., and Lanzavecchia, A. 1994. Efficient presentation of soluble antigen by cultured human dendritic cells is maintained by granulocyte/macrophage colony-stimulating factor plus interleukin 4 and downregulated by tumor necrosis factor alpha. J. Exp. Med. 179:1109-1118.

33. Von Bergwelt-Baildon, M.S., et al. 2006. CD25 and indoleamine 2,3-dioxygenase are up-regulated by prostaglandin E2 and expressed by tumor-associated dendritic cells in vivo: additional mechanisms of T-cell inhibition. Blood. 108:228-237.

34. McCaffrey, R.L., et al. 2004. A specific gene expression program triggered by Gram-positive bacteria in the cytosol. Proc. Natl. Acad. Sci. U. S. A. 101:11386-11391.
35. Tusher, V.G., Tibshirani, R., and Chu, G. 2001. Significance analysis of microarrays applied to the ionizing radiation response. Proc. Natl. Acad. Sci. U. S. A. 98:5116-5121.

36. Tibshirani, R., Hastie, T., Narasimhan, B., and Chu, G. 2002. Diagnosis of multiple cancer types by shrunken centroids of gene expression. Proc. Natl. Acad. Sci. U. S. A. 99:6567-6572.

37. Carlin, J.M., Borden, E.C., Sondel, P.M., and Byrne, G.I. 1989. Interferon-induced indoleamine 2,3-dioxygenase activity in human mononuclear phagocytes. J. Leukoc. Biol. 45:29-34.

38. Turco, J., and Winkler, H.H. 1986. Gamma-interferon-induced inhibition of the growth of Rickettsia prowazekii in fibroblasts cannot be explained by the degradation of tryptophan or other amino acids. Infect. Immun. 53:38-46.

39. Mackler, A.M., Barber, E.M., Takikawa, O., and Pollard, J.W. 2003. Indoleamine 2,3-dioxygenase is regulated by IFN-gamma in the mouse placenta during Listeria monocytogenes infection. J. Immunol. 170:823-830.

40. Braun, D., Longman, R.S., and Albert, M.L. 2005. A two-step induction of indoleamine 2,3 dioxygenase (IDO) activity during dendritic-cell maturation. Blood. 106:2375-2381.

41. Smith, W.L., DeWitt, D.L., and Garavito, R.M. 2000. Cyclooxygenases: structural, cellular, and molecular biology. Annu. Rev. Biochem. 69:145-182.

42. Kabashima, K., et al. 2003. Prostaglandin E2-EP4 signaling initiates skin immune responses by promoting migration and maturation of Langerhans cells. Nat. Med. 9:744-749.

43. Grell, M., et al. 1995. The transmembrane form of tumor necrosis factor is the prime activating ligand of the $80 \mathrm{kDa}$ tumor necrosis factor receptor. Cell. 83:793-802.

44. Rose, F., et al. 2001. Human endothelial cell activation and mediator release in response to Listeria monocytogenes virulence factors. Infect. Immun. 69:897-905.

45. Leimeister-Wachter, M., Haffner, C., Domann, E., Goebel, W., and Chakraborty, T. 1990. Identification of a gene that positively regulates expression of listeriolysin, the major virulence factor of listeria monocytogenes. Proc. Natl. Acad. Sci. U. S. A. 87:8336-8340.

46. Fiedler, F. 1988. Biochemistry of the cell surface of Listeria strains: a locating general view. Infection. 16(Suppl. 2):S92-S97.

47. Cabeen, M.T., and Jacobs-Wagner, C. 2005. Bacterial cell shape. Nat. Rev. Microbiol. 3:601-610.

48. Takeuchi, O., et al. 1999. Differential roles of TLR2 and TLR4 in recognition of gram-negative and gram-positive bacterial cell wall components. Immunity. 11:443-451.

49. Terness, P., et al. 2002. Inhibition of allogeneic T cell proliferation by indoleamine 2,3-dioxygenase-expressing dendritic cells: mediation of suppression by tryptophan metabolites. J. Exp. Med. 196:447-457.

50. Tzianabos, A.O., and Kasper, D.L. 2002. Role of $\mathrm{T}$ cells in abscess formation. Curr. Opin. Microbiol. 
5:92-96.

51. Tsunawaki, S., Sporn, M., Ding, A., and Nathan, C. 1988. Deactivation of macrophages by transforming growth factor-beta. Nature. 334:260-262.

52. Volkman, H.E., et al. 2004. Tuberculous granuloma formation is enhanced by a mycobacterium virulence determinant. PLoS Biol. 2:e367.

53. Lecuit, M., and Cossart, P. 2002. Genetically-modified-animal models for human infections: the Listeria paradigm. Trends Mol. Med. 8:537-542.

54. Grohmann, U., et al. 2001. IL-6 inhibits the tolerogenic function of CD8 alpha+ dendritic cells expressing indoleamine 2,3-dioxygenase. J. Immunol. 167:708-714.

55. Munn, D.H., et al. 2002. Potential regulatory function of human dendritic cells expressing indoleamine 2,3-dioxygenase. Science. 297:1867-1870.

56. Terness, P., Chuang, J.J., and Opelz, G. 2006. The immunoregulatory role of IDO-producing human dendritic cells revisited. Trends Immunol. 27:68-73.

57. Kaufmann, S.H. 2002. Protection against tuberculosis: cytokines, T cells, and macrophages. Ann Rheum. Dis. 61(Suppl. 2):ii54-ii58.

58. Zganiacz, A., et al. 2004. TNF- $\alpha$ is a critical negative regulator of type 1 immune activation during intracellular bacterial infection. J. Clin. Invest. 113:401-413. doi:10.1172/JCI200418991.

59. Kindler, V., Sappino, A.P., Grau, G.E., Piguet, P.F., and Vassalli, P. 1989. The inducing role of tumor necrosis factor in the development of bactericidal granulomas during BCG infection. Cell. 56:731-740.

60. Flynn, J.L., et al. 1995. Tumor necrosis factor-alpha is required in the protective immune response against Mycobacterium tuberculosis in mice. Immunity. 2:561-572.

61. Ehlers, S., et al. 2003. The lymphotoxin beta receptor is critically involved in controlling infections with the intracellular pathogens Mycobacterium tuberculosis and Listeria monocytogenes. J. Immunol. 170:5210-5218.

62. Keane, J., et al. 2001. Tuberculosis associated with infliximab, a tumor necrosis factor alpha-neutralizing agent. N. Engl. J. Med. 345:1098-1104.

63. Slifman, N.R., Gershon, S.K., Lee, J.H., Edwards, E.T., and Braun, M.M. 2003. Listeria monocytogenes infection as a complication of treatment with tumor necrosis factor alpha-neutralizing agents. Arthritis Rheum. 48:319-324.

64. Wallis, R.S., and Ehlers, S. 2005. Tumor necrosis factor and granuloma biology: explaining the differential infection risk of etanercept and infliximab. Semin. Arthritis Rheum. 34:34-38.

65. Furst, D.E., Wallis, R, Broder, M., and Beenhouwer, D.O. 2006. Tumor necrosis factor antagonists: different kinetics and/or mechanisms of action may explain differences in the risk for developing granulomatous infection. Semin. Arthritis Rheum. In press.

66. Wolf, A.M., et al. 2004. Overexpression of indoleamine 2,3-dioxygenase in human inflammatory bowel disease. Clin. Immunol. 113:47-55.

67. Young, D.A., Lowe, L.D., and Clark, S.C. 1990. Comparison of the effects of IL-3, granulocyte-macrophage colony-stimulating factor, and macrophage colony-stimulating factor in supporting monocyte differentiation in culture. Analysis of macrophage antibody-dependent cellular cytotoxicity. J. Immu nol. 145:607-615

68. Akagawa, K.S., et al. 1996. Generation of $\mathrm{CD} 1+\mathrm{RelB}+$ dendritic cells and tartrate-resistant acid phosphatase-positive osteoclast-like multinucleated giant cells from human monocytes. Blood. 88:4029-4039.

69. Utermohlen, O., Karow, U., Lohler, J., and Kronke, M. 2003. Severe impairment in early host defense against Listeria monocytogenes in mice deficient in acid sphingomyelinase. J. Immunol. 170:2621-2628.
70. Ouadrhiri, Y., Scorneaux, B., Sibille, Y., and Tulkens, P.M. 1999. Mechanism of the intracellular killing and modulation of antibiotic susceptibility of Listeria monocytogenes in THP-1 macrophages activated by gamma interferon. Antimicrob. Agents Chemother. 43:1242-1251.

71. Wadsworth, S.J., and Goldfine, H. 2002. Mobilization of protein kinase $\mathrm{C}$ in macrophages induced by Listeria monocytogenes affects its internalization and escape from the phagosome. Infect. Immun. 70:4650-4660.

72. Morath, S., Geyer, A., and Hartung, T. 2001. Structure-function relationship of cytokine induction by lipoteichoic acid from Staphylococcus aureus. J. Exp. Med. 193:393-397.

73. Morath, S., Stadelmaier, A., Geyer, A., Schmidt, R.R., and Hartung, T. 2002. Synthetic lipoteichoic acid from Staphylococcus aureus is a potent stimulus of cytokine release. J. Exp. Med. 195:1635-1640.

74. Debey, S., et al. 2004. Comparison of different isolation techniques prior gene expression profiling of blood derived cells: impact on physiological responses, on overall expression and the role of different cell types. Pharmacogenomics. J. 4:193-207.

75. Chemnitz, J.M., et al. 2006. Prostaglandin E2 impairs CD4+ $\mathrm{T}$ cell activation by inhibition of lck: implications in Hodgkin's lymphoma. Cancer Res. 66:1114-1122.

76. Ihaka, R., and Gentleman, R.R. 1996. A language for data analysis and graphics. Journal of Computational and Graphical Statistics. 5:299-314.

77. Dietzsch, J., Gehlenborg, N., and Nieselt, K. 2006. Mayday-a microarray data analysis workbench. Bioinformatics. 22:1010-1012.

78. Saric, T., et al. 2001. Major histocompatibility complex class I-presented antigenic peptides are degraded in cytosolic extracts primarily by thimet oligopeptidase. J. Biol. Chem. 276:36474-36481. 